\title{
$\mathrm{SCR}$ 공정에서 반응기 내부의 유동 균일화를 위한 수치적 연구
}

정유진 ${ }^{1}$, 홍성길 ${ }^{1}$, 김민철 ${ }^{2}$, 이재정 ${ }^{2}$, 이강우 ${ }^{2}$, 손병현 $3^{*}$

${ }^{1}$ 씨이테크(주) 연구개발센터, ${ }^{2}$ (주)유성 중앙연구소, ${ }^{3}$ 한서대학교 환경공학과

\section{Numerical Study for Flow Uniformity in Selective Catalytic Reduction(SCR) Process}

\author{
Yu-Jin Jung ${ }^{1}$, Sung-Gil Hong ${ }^{1}$, Min-Choul Kim ${ }^{2}$, Jae-Jeong Lee ${ }^{2}$, Gang-Woo Lee ${ }^{2}$ \\ and Byung-Hyun Shon $^{3^{*}}$ \\ ${ }^{1}$ C.E.Tech Co. Ltd., R\&D Center, ${ }^{2}$ Yoosung Co. Ltd., R\&D Center \\ ${ }^{3}$ Dept. of Environmental Engineering, Hanseo University
}

\begin{abstract}
요 약 $\mathrm{SCR}$ 의 $\mathrm{NOx}$ 제거 성능은 촉매 요인(촉매 구성물질, 형태, 공간속도 등), 배가스의 온도, 유속 분포 등의 다 양한 인자에 의해 좌우되며, 이 중 촉매층으로 유입되는 유동의 균일도는 가장 중요한 요소가 된다. 본 연구에서는 3 차원 수치 해석 기법을 이용하여 설계 단계의 SCR 반응기 내의 유동 특성을 모사하여 기류 균일도 여부를 확인하였 다. 또한 SCR 반응기 내의 유동 균일도를 최적화시키기 위해 가이드 베인과 배플 및 다공판 등을 설치하였을 경우 반응기 내부 유동 및 촉매층의 기류 균일도에 미치는 영향에 대해 연구를 수행하였다. 유동 개선을 위해 인입 덕트 곡관부에 가이드 베인을 설치하여 처리가스를 적절하게 배분시키고, 반응기 상단에 배플을 설치한 결과 반응기 내부 유동의 편류 개선에 매우 효과적임을 알 수 있었다. 또한 다공판을 예비 촉매층 하단부에 추가로 설치함에 따라 유동 을 한번 더 완충시킬 수 있어 기류 균일도가 매우 양호해짐을 확인 할 수 있었다.
\end{abstract}

\begin{abstract}
Performance of NOx removal in SCR(Selective Catalytic Reduction) process depends on such various factors as catalyst factors (catalyst composition, catalyst form, space velocity, etc.), temperature of exhaust gas, and velocity distribution of exhaust gas. Especially the flow uniformity of gas stream flowing into the catalyst layer is believed to be the most important factor to influence the performance. In this research, the flow characteristics of a SCR process at design stage was simulated, using 3-dimensional numerical analysis method, to confirm the uniformity of the gas stream. In addition, the effects of guide vanes, baffles, and perforated plates on the flow uniformity for the inside and catalyst layer of the reactor were studied in order to optimize the flow uniformity inside the SCR reactor. It was found that the installation of a guide vane at the inlet duct L-tube part and the installation of a baffle at the upper part is very effective in avoiding chaneling inside the reactor. It was also found that additional installation of a perforated plate at the lower part of the potential catalyst layer buffers once more the flow for very uniform distribution of the gas stream
\end{abstract}

Key Words : SCR, NOx, CFD, Flow Uniformity, Channeling

1. 서론

국내 에너지 소비량은 경제 발전에 비례하여 지속적으
로 증가하고 있으며, 이에 따라 연료수급 측면에서 대체 에너지원의 개발이 완료될 때까지는 화석 연료의 사용이 지속적으로 증가될 것으로 전망된다. 화석연료는 연소 과

본 연구는 국토해양부 지역기술혁신 연구개발사업의 연구비지원(과제번호 08 지역기술혁신B-03)에 의해 수행되었습니다. "교신저자 : 손병현(bhshon@hanseo.ac.kr)

접수일 11년 06월 30일수정일 (1차 11년 08월 22일, 2차 11년 09월 22일)

게재확정일 11 년 10 월 06 일 
정에서 황산화물(SOx), 질소산화물(NOx)을 포함한 많은 대기오염물질을 생성하며, 이는 산성비, 건축물의 부식, 토양 및 수질의 오염, 국민건강의 저해 등에 대한 복합적 인 원인으로 작용한다.

NOx 제어 기술로는 크게 연소 전 탈질, 연소 개선 및 연소 후 탈질 기술로 구분할 수 있으며, 연소 후 탈질 기 술에 속하는 선택적 촉매 환원법(Selective Catalytic Reduction, SCR)은 촉매를 사용하여 NOx를 환원하는 대 표적인 배연탈질기술이다. SCR은 배가스 중에 포함되어 있는 $\mathrm{NOx}$ 를 촉매층(catalyst layer)에서 $\mathrm{NH}_{3}$ 와 반응시켜 무해한 질소 $\left(\mathrm{N}_{2}\right)$ 와 물 $\left(\mathrm{H}_{2} \mathrm{O}\right)$ 로 전환하는 기술이다. 환원제 로는 $\mathrm{NH}_{3}$ 와 우레아(urea)가 많이 사용된다. SCR의 $\mathrm{NOx}$ 저감 성능은 촉매 요인(촉매 구성물질, 형태, 공간속도 등)과 배가스의 온도, 유속 분포, 공정 운전 조건 등의 다 양한 인자에 의해 좌우된다 $[1,2]$.

촉매의 우수성이 보장되는 경우 $\mathrm{SCR}$ 의 반응 성능은 무수암모니아수의 농도 분포와 균일한 유입속도가 반응 기에서의 환원효율을 결정하는 중요한 요소가 되며, 특히 촉매층으로 유입되는 유동의 균일도는 가장 중요한 요소 가 된다. 유동이 균일하지 않을 경우 촉매 전단에 편류가 발생하게 될 것이며 일정 촉매만 사용하게 되어 촉매 사 용주기 감소 및 $\mathrm{SCR}$ 성능 저하를 초래할 수 있기 때문이 다.

촉매층에 전달되는 균일한 기류 분포를 확보하기 위해 서는 처리가스가 반응기 상부로부터 직접 유입되는 것이 가장 바람직할 수 있으나, 실제 현장에서는 설치 공간 문 제로 인하여 상부 인입 구조와 같은 합리적인 설계가 불 가능하여 측면 인입 구조로 대부분 설계하게 된다. 이러 한 이유로 유동의 균일화를 보장하기 위해 많은 제한적 조건이 따르게 되므로 $\mathrm{SCR}$ 내의 유동 균일화를 위해서 는 필요시에 가이드 베인(guide vane)이나 다공판 (perforated plate) 등과 같은 유동을 변경시켜줄 수 있는 장치가 설치된다[3].

본 연구에서는 설치 공간상의 제약 때문에 처리가스가 반응기 상부 측면에서 인입되는 가장 일반적인 구조의 $\mathrm{SCR}$ 반응기 내 유동 특성을 3 차원 수치 해석 기법을 이 용하여 모사하여 기류 균일도 여부를 확인하고, $\mathrm{SCR}$ 내 의 유동 균일도를 최적화시키기 위한 목적으로 가이드 베인과 배플, 다공판 설치에 따른 유동 특성을 해석하여 기류 균일도에 미치는 영향에 대해 연구를 수행하였다.

\section{2. 수치해석}

\subsection{1 기초방정식}

유체의 유동에 대한 물리적인 특성을 나타내는 기본적 인 법칙은 질량, 운동량 및 에너지 보존 법칙들이다. 정상 상태, 비압축성 기체라 가정할 때 일반적인 물리량의 수 송방정식은 다음과 같다[4].

$\operatorname{div}\left(\rho \mathrm{V} \Phi_{\mathrm{i}}-\Gamma_{\Phi \mathrm{i}} \operatorname{grad} \Phi_{\mathrm{i}}\right)=\mathrm{S}_{\Phi \mathrm{i}}(1)$ 여기에서 $\mathrm{V}$ 는 속도벡 터(velocity vector)이고 $\Gamma_{\Phi i}$ 는 확산 계수(diffusion coefficient)이다. $\mathrm{S}_{\Phi i}$ 는 부력항( $\left.\mathrm{S}_{\text {buoyancy }}\right)$ 을 제외한 비정상 항, 압력구배 등을 포함한 모든 source term을 나타낸다.

\subsection{2 난류 모델}

난류 모델에는 난류점성계수를 취급하는 방법에 따라 여러 가지 모델이 있는데, 본 연구에서는 Launder와 Spalding에 의해 제시된 Standard k-ع turbulence model을 사용하였다.

난류 유동은 매우 불규칙하고, 비정상 3 차원 거동을 하므로 난류 유동과 관련된 유동 현상을 수치적으로 정 확하게 예측하거나 설명하기는 어려워 고 레이놀즈수 유 동에서 발생되는 난류의 물리량 수송방정식인 Reynoldsaveraged Navier-Stokes 방정식을 직접 풀 수는 없다[2]. 따라서 난류를 해석하기 위해 난류 모델을 도입하게 된 다. 난류 모델로는 Reynolds-averaged Navier-Stokes 방정 식과 함께 표준 k- $\varepsilon$ 모델을 사용하였고, 표준 $\mathrm{k}-\varepsilon$ 모델은 점성에 의한 응력이 속도의 변형률에 비례한다는 가정 하에 난류 에너지와 소산률을 통해 난류 점성 계수를 취 급한다.

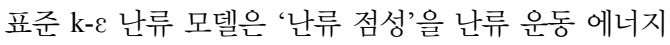
$\mathrm{k}$ 와 난류의 소산률 $\varepsilon$, 이 두 가지 변수로 표현한다.

$$
\mu_{t}=\frac{C_{\mu} \rho k^{2}}{\epsilon}
$$

난류 점성 계수를 구하기 위해서는 난류 에너지와 소 산률을 알아야 한다. 난류 운동 에너지 $(k)$ 방정식은,

$$
\frac{\partial}{\partial x_{i}}\left(\rho u_{i} k\right)=\frac{\partial}{\partial x_{i}}\left(\frac{\mu_{t}}{\sigma_{k}} \frac{\partial k}{\partial x_{i}}\right)+G_{k}+G_{b}-\rho \epsilon
$$

난류 소산률( $(\varepsilon)$ 방정식은 식 (4)와 같고 여기서 $\mathrm{G}_{\mathrm{k}}$ 는 난류 생성항으로서 식 (5)와 같다.

$$
\begin{aligned}
& \frac{\partial}{\partial x_{i}}\left(\rho u_{i} \epsilon\right)= \\
& \frac{\partial}{\partial x_{i}}\left[\left(\mu+\frac{\mu_{t}}{\sigma_{k}}\right) \frac{\partial \epsilon}{\partial x_{k}}\right]+C_{1} \frac{\epsilon}{k} P-C_{2} \rho \frac{\epsilon^{2}}{k} \\
& G_{k}=\mu_{t}\left(\frac{\partial u_{i}}{\partial x_{j}}+\frac{\partial u_{j}}{\partial x_{i}}\right) \frac{\partial u_{i}}{\partial x_{j}}
\end{aligned}
$$

\section{1 수치해석개요}




\subsection{3 수치해석 방법}

본 연구에 사용된 상용 소프트웨어인 FLUENT에서는 이산화 방법으로 유한 체적법(Finite-volume method)을 사용하고 있다. 모든 수치 해석은 상류 차분 도식 (Upwind differencing scheme)과 엇갈림 격자계(Staggered grids)를 이용하여 수행하였다. 압력장을 구하기 위해 연 속 방정식과 운동량 방정식을 조합시키는 방법으로 SIMPLE(Semi-Impicit Method Pressure-Linked Equations) 알고리즘을 사용하였고, 벽면과 고체 표면에서의 전단 응 력은 벽함수(Wall function)를 이용하여 계산하였다. 촉매 층은 실제 형상과 공극을 모델링하여 구현하는 것이 불 가능하므로 Porous jump model을 이용하여 다공성 물질 로 가정하고 국부 유속에 대한 단위 면적당 압력강하로 계산하였다[6].

\section{2 수치해석 조건}

\subsection{1 설계 단계 모델 및 경계 조건}

본 연구는 실제로 조업 중인 $\mathrm{SCR}$ 반응기의 현 상황을 진단하고 성능 개선을 도모하기 위한 것이다. 이를 위해, 그림 1 의 설계도면을 바탕으로 그림 2 와 같이 설계도면 과 똑같은 형상으로 3 차원 모형을 구현하였고 수치 계산 을 위한 격자 형상(grid configuration) 모습도 함께 나타 내었다. 정확한 유동 형상을 확인해야 하는 반응기 내부 및 촉매층은 육면체(Hexa-hedron) 격자계를 사용하였고, 그 외 형상이 복잡한 구간에는 사면체(Tetra-hedron) 격자 계를 사용하였으며 반응기 형상을 구현하는데 사용된 격 자수는 총 $1,058,604$ 개이다.

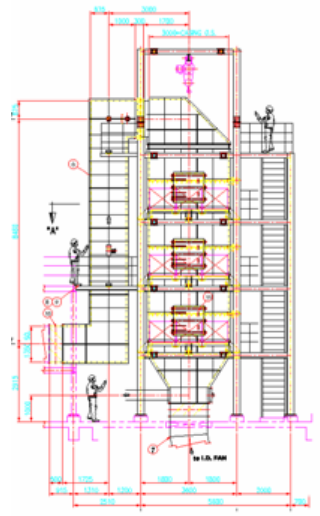

[Side view]

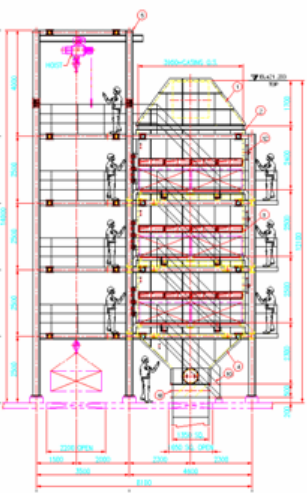

[Front view]
[그림 1] SCR 구조의 설계 도면.

[Fig. 1] Drawings of the SCR structure.

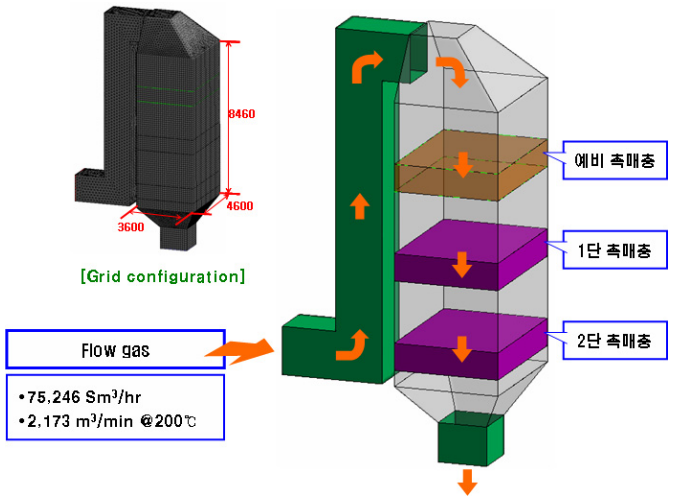

[그림 2] SCR 반응기 설계 단계의 수치해석을 위한 로의 제어체적과 그리드.

[Fig. 2] Control volume and grid of SCR reactor for a computational fluid dynamics.

수치 해석 대상 반응기의 처리가스 유량은 75,246 $\mathrm{Sm}^{3} / \mathrm{hr}\left(2,173 \mathrm{~m}^{3} / \mathrm{min}\right.$, at $\left.200^{\circ} \mathrm{C}\right)$ 이며, 처리가스가 반응기 상부 측면으로 유입되어 $\mathrm{SCR}$ 촉매층을 통과하면서 질소 산화물이 제거되고 하부로 배출된다. 촉매층은 총 3 단으 로 구성되는데 최상단 촉매층은 예비 촉매층이므로 실제 조업이 되는 촉매층은 2 단이다.

\subsection{2 설계 변경 모델}

$\mathrm{SCR}$ 의 설계 초기 모델의 유동 균일도를 최적화시키기 위한 설계를 목적으로 표 1과 같이 가이드 베인과 배플, 다공판 설치에 따른 유동 특성을 해석하여 기류 균일도 에 미치는 영향에 대하여 연구를 수행하였다[7].

[표 1] 설계 변경 모델 case

[Table 1] A case study for the change of design.

\begin{tabular}{|l|l|l|}
\hline 조건 & 설계 변경 & 설계 변경 개념도 \\
\hline case-1 & $\begin{array}{l}\text { 인입 덕트에 가이드 } \\
\text { 베인 설치 } \\
\text { 반응기 상단 2단 배 } \\
\text { 플 설치 }\end{array}$ \\
\hline case-2 & $\begin{array}{l}\text { 인입 덕트에 가이드 } \\
\text { 베인 설치 } \\
\text { 반응기 상단 3단 배 } \\
\text { 플 설치 }\end{array}$ \\
\hline
\end{tabular}




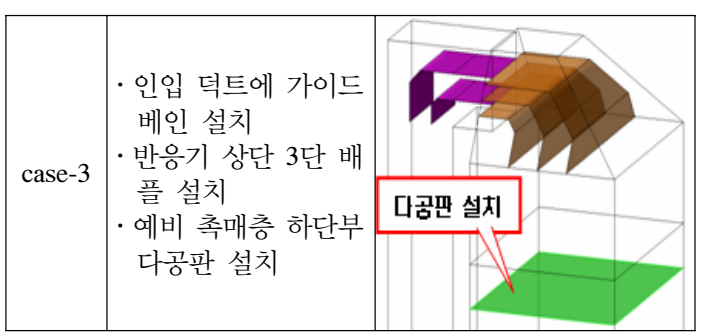

\section{3. 결과 및 고찰}

\section{1 설계 단계 모델}

\subsection{1 반응기 내 속도 분포}

그림 3은 설계 초기 모델의 반응기 내 속도 분포를 예 측한 결과이다. 그림 $3(\mathrm{~b})$ 의 수평방향 속도 분포에서 볼 수 있듯이, 인입 덕트의 곡관에 의해 반응기 내부에 심한 편류가 형성되고 있었으며, 특히 1단 촉매층에 편류가 심 하여 촉매층 상부에서의 유속 편차가 매우 심한 것으로 예측되었다. 그러나 2 단 촉매층은 거리에 의해 유동이 다 소 발달하고 촉매층에 의한 압력손실이 완충역할을 함에 따라 유속 편차가 크게 줄어든 것을 확인할 수 있었다.

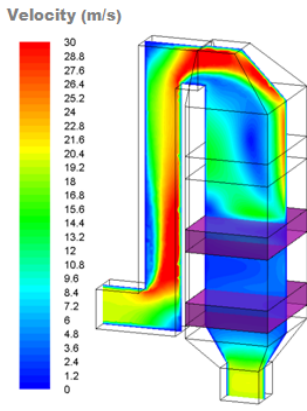

(a) 수직단면

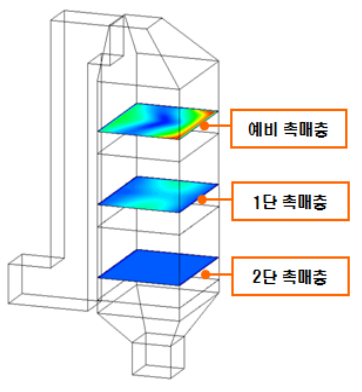

(b) 수평단면
[그림 3] 설계 단계의 반응기 내부 속도 분포

[Fig. 3] Velocity distribution of waste gas.

\subsection{2 반응기 내 기류 분포 및 유선 형상}

그림 4는 반응기 내 기류 분포 및 유선 형상을 나타낸 것이다. 그림 4 와 같이 인입 덕트의 곡관에 의해 반응기 내부 한쪽으로 심한 편류가 형성되면서 편류 반대편으로 사영역(dead-zone)이 발생하여 부상 기류가 형성되고 있 음을 알 수 있었다. 그러나 속도 분포와 마찬가지로, 2단 촉매층은 거리에 의해 유동이 다소 발달하여 촉매층에 의한 압력손실이 완충역할을 함에 따라 기류의 직진성은 비교적 양호한 것을 확인할 수 있었다.

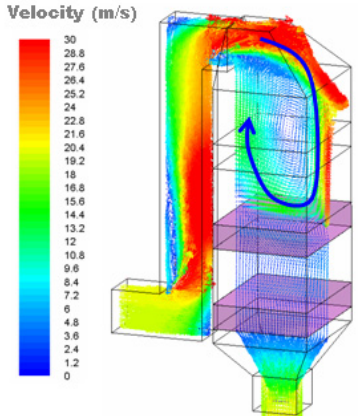

(a) 기류 분포

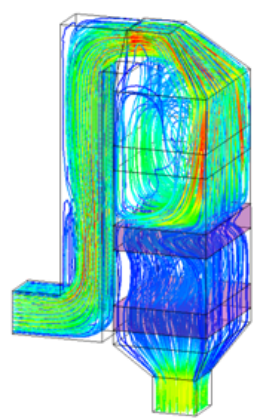

(b) 유선
[그림 4] 설계 단계의 반응기 내부 기류 분포 및 유선 [Fig. 4] Flow pattern and streamline of waste gas.

\subsection{3 촉매층 상단 인입 유속}

그림 5 는 1 단 촉매층 상단에 유입되는 기류의 유속값 을 plotting한 결과이다. 유속이 약 $3 \sim 7.5 \mathrm{~m} / \mathrm{s}$ 수준으로 분포하고 있어 촉매층으로 전달되는 유량 편차가 매우 심한 것을 확인할 수 있다.

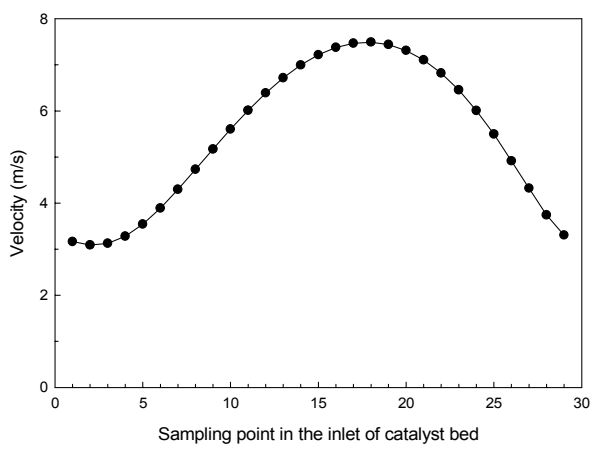

[그림 5] 1단 촉매층 상부의 유입속도

[Fig. 5] Inlet velocity into the upper part of the first catalyst layer.

따라서 본 SCR 반응기의 설계 초기 모델은 편류가 심 하게 발생하여 1 단 촉매층에서의 기류 균일도가 매우 불 량한 상태이며, 이는 곧 촉매 성능을 저하시켜 De-NOx 효율이 저하될 수 있으므로 유동의 균일도를 개선할 수 있는 설계 변경이 반드시 필요할 것으로 판단된다.

\section{2 설계 변경 모델}

\subsection{1 반응기 내 유동 예측 결과}

설계 초기 모델의 기류 균일도 개선을 위해 기류 안내 용 가이드 베인과 배플, 다공판을 설치한 결과 그림 6 그림 9 와 같이 1 단 촉매층에서의 유속 편차가 크게 줄어 드는 것을 확인할 수 있었다. 


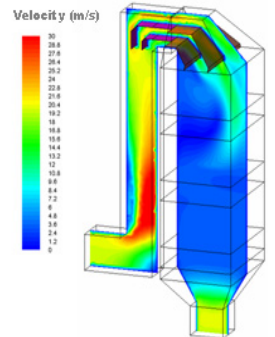

(a) case-1

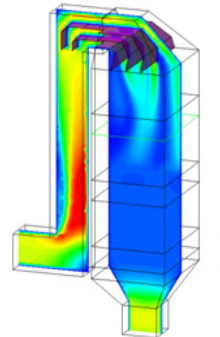

(b) case-2

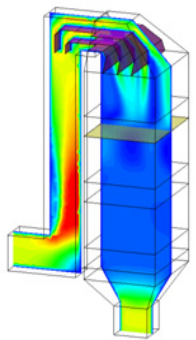

(c) case-3
[그림 6] 설계 변경 시 반응기 내부의 수직 단면 속도 분포

[Fig. 6] Velocity distribution(vertical section) of waste gas after change of design.

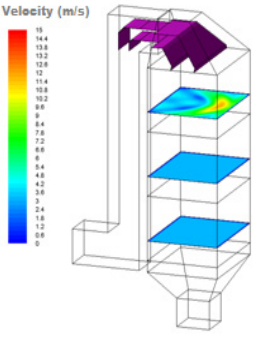

(a) case-1

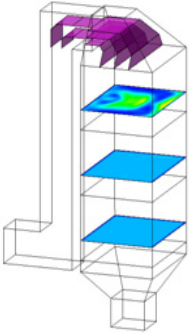

(b) case-2

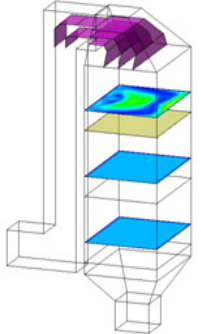

(c) case-3
[그림 7] 설계 변경 시 반응기 내부의 수평 단면 속도 분포

[Fig. 7] Velocity distribution(horizontal section) of waste gas after change of design.

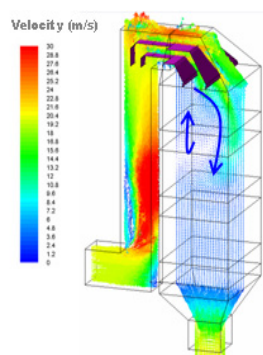

(a) case- 1

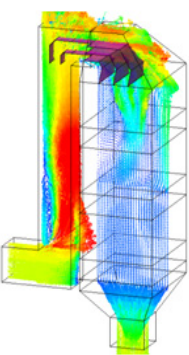

(b)case-2

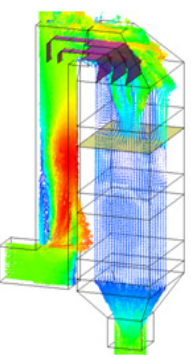

(c)case-3
[그림 8] 설계 변경 시 반응기 내부 기류 분포

[Fig. 8] Flow pattern of waste gas after change of design.

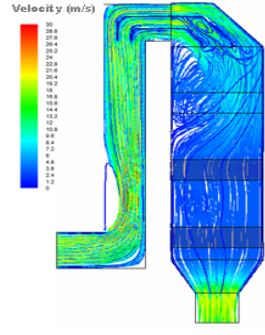

(a) case-1

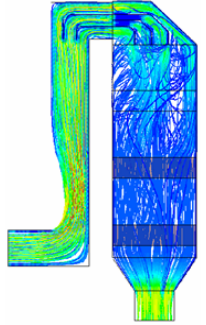

(b) case-2

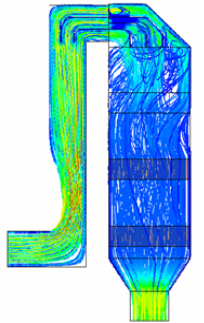

(c) case-3
[그림 9] 설계 변경 시 반응기 내부 유선 형상

[Fig. 9] Streamline patterns of waste gas after change of design.
그러나, 그림 8 그림 9에서 볼 수 있듯이, case-1의 경 우에는 설계 초기 모델에 비해 편류가 많이 개선되긴 하 였으나 여전히 기류가 한쪽으로 편향됨에 따라 미소하게 사영역이 형성되는 것을 확인 할 수 있었다. 따라서 1 단 촉매층에서의 기류 균일도에도 미소하게 영향을 줄 수 있을 것으로 예상된다. Case-2와 같이 배플을 3 단으로 설 치했을 경우 사영역(dead zone) 해소에 따른 부상 기류 형성을 억제하는데 효과적일 수 있음을 유선 형상을 통 해 확인할 수 있었다. 또한 case-3과 같이 반응기 내부에 다공판을 설치한 경우(배플 3단 설치 포함) 유동이 완충 됨에 따라 유동의 직진성을 더욱 보완할 수 있는 것으로 유선 형상을 통해 확인할 수 있었다.

\subsection{2 설계 변경 결과 종합}

설계 변경 후 인입 덕트 곡관부에 가이드 베인을 설치 하여 처리가스를 적절하게 배분시키고, 반응기 상단에 배 플을 설치한 결과, 반응기 내부 유동의 편류 개선에 효과 적임을 유선 형상을 통해 확인할 수 있었다.

단, 그림 10 과 같이 본 연구 대상 설비의 구조에서는 반응기 상부에 2 단 배플을 설치하는 것보다 3 단 배플을 설치하는 것이 반응기 내부 사영역 형성을 억제하여 1 단 촉매층에서의 기류 균일도를 더욱 향상시킬 수 있는 것 으로 예측되었다. 또한 다공판을 예비 촉매층 하단부 위 치에 추가로 설치함에 따라 유동을 한번 더 완충시킬 수 있어 유동의 직진성을 더욱 보완할 수 있어 1 단 촉매층에 서의 기류 균일도가 더욱 개선되어짐을 알 수 있었다.

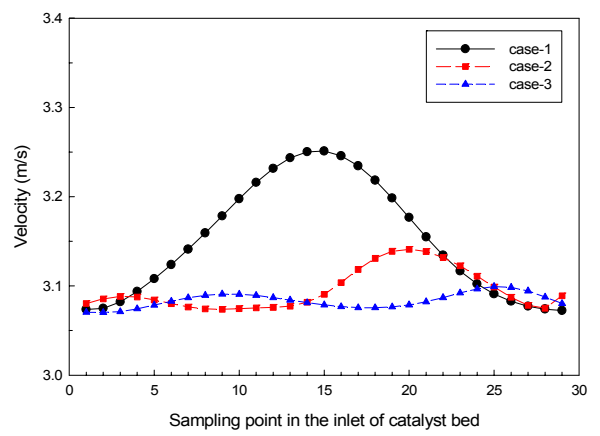

[그림 10] 각 case별 1단 촉매층 상단 인입 유속

[Fig. 10] Inlet velocity into the upper part of the first catalyst layer with 3 cases.

\section{4. 결론}

본 연구에서는 보편적으로 설계되어지는 $\mathrm{SCR}$ 반응기 
구조인 반응기 상부 측면에서 처리가스가 인입되는 형태 의 SCR 반응기에 대하여 내부 편류 형성이 예상되는 바, 3 차원 수치 해석 기법을 이용하여 반응기 내 유동 특성을 모사하여 기류 균일도 여부를 확인하고, SCR 반응기 내 부의 유동 균일도를 최적화하기 위해 가이드 베인과 배 플, 다공판을 반응기 내부에 설치했을 경우 유동 및 촉매 층의 기류 균일도에 미치는 영향에 대하여 연구를 수행 한 결과 다음과 같은 결론을 얻을 수 있었다.

1. 본 SCR 반응기의 설계 단계 모델에 대하여 유동 특 성을 해석한 결과, 편류가 심하게 발생하여 1단 촉 매층에서의 기류 균일도가 매우 불량한 상태이며, 이는 곧 촉매 성능을 저하시켜 De-NOx 효율이 저 하될 수 있으므로 유동의 균일도를 개선할 수 있는 설계 변경이 필요한 것으로 예측되었다.

2. 유동 개선을 위해 인입 덕트 곡관부에 가이드 베인 을 설치하여 처리가스를 적절하게 배분시키고 반응 기 상단에 3 단 배플을 설치하여 모사해 본 결과, 반 응기 내부 유동의 편류 개선에 매우 효과적임을 알 수 있었다. 또한 다공판을 예비 촉매층 하단부 위치 에 추가로 설치함에 따라 유동을 한번 더 완충시킬 수 있어 기류 균일도가 매우 양호해짐을 알 수 있었 다.

\section{Nomenclatures}

$\mathrm{V}$ : 속도 벡터

$\Gamma_{\Phi \mathrm{i}}$ : 확산 계수

$\mathrm{S}_{\Phi \mathrm{i}}$ : 부력항을 제외한 비정상항, 압력구배 등을 포함 한 모든 source term

$\mathrm{k}$ : 난류 운동 에너지

$\varepsilon$ : 소산률

$\mathrm{G}_{\mathrm{k}}$ : 난류 생성항

$\mathrm{R}$ : 잉여치

$\mathrm{Gb}$ : 부력항

$\mu_{\mathrm{t}}$ : 난류 점성 계수

$\mathrm{C}_{\mu}, \mathrm{C}_{\varepsilon 1}, \mathrm{C}_{\varepsilon 2}, \sigma_{\mathrm{k}}, \sigma_{\varepsilon}$ : 경험적 실험상수

$\rho:$ 밀도

$\Phi_{\mathrm{i}}$ : 지배 방정식의 의존 변수

$\mathrm{g}$ : 중력 가속도

$\mathrm{T}$ : 온도(K)

$\mathrm{u}$ : $\mathrm{X}$ 방향 속도 성분

$\mathrm{v}$ : Y방향 속도 성분

$\mathrm{w}$ : $\mathrm{Z}$ 방향 속도 성분

\section{References}

[1] Gang-Woo Lee, Byung-Hyun Shon, Jeong-Gun Yoo, Jong-Hyeon Jung, and Kwang-Joong Oh, "The influence of mixing between $\mathrm{NH}_{3}$ and $\mathrm{NO}$ for a De-NOx reaction in the SNCR process", Journal of Industrial and Engineering Chemistry, Vol. 14, No. 4, pp. 457-467, July 2008.

[2] Thanh D.B. Nguyen, Young-Il Lim, Won-Hyeon Eom, Seong-Joon Kim, Kyung-Seun Yoo, "Experiment and CFD simulation of hybrid SNCR-SCR using urea solution in a pilot-scale reactor", Computers \& Chemical Engineering, Vol. 34, Issue 10, pp. 1580-1589, 2010.

[3] L.K. Hjertager, B.H. Hjertager, T. Solberg, "CFD modeling of fast chemical reactions in turbulent liquid flows", Computer Aided Chemical Engineering, Vol. 9, pp. 159-164, 2001.

[4] Yu-Jin Jung, "The Fundamental Study about Optimum Design of Natural Gravity Ventilator", Changwon University, master's thesis, 2001.

[5] B. E. Launder and D. B. Spalding, "The numerical computation of turbulent flows", Computer Methods in Applied Mechanics and Engineering, Vol. 3, No. 2, pp. 269-289, 1974.

[6] Patankar S.V., Numerical Heat Transfer and Fluid Flow, Hemisphere Publishing Corp, 1980

[7] Jin-Uk Kim, Yu-Jin Jung, Jeong-Kun Yoo and Byung-Hyun Shon, “A Study on Numerical Calculations of Hybrid Air Pollution Control System Coupled with SDR and Bag Filter(II) - Structural Improvement", Journal of the Korea Academia-Industrial cooperation Society, Vol. 12, No. 2, pp. 985-992, 2011.

\section{정 유 진(Yu-Jin Jung)}

[정회원]

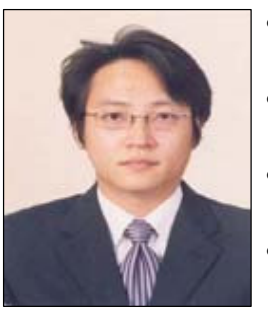

- 2000년 2월 : 창원대학교 환경공 학과(공학사)

- 2002년 2월 : 창원대학교 환경공 학과(공학석사)

- 2002년 9월 2010년 3월 : 크 린에어테크놀로지(주)

- 2010년 3월 현재 : 씨이테크

(주) 컨설팀 수석연구원

<관심분야>

산업환기기술, 대기오염제어기술, 대기오염모델링 
홍 성 길(Sung-Gil Hong)

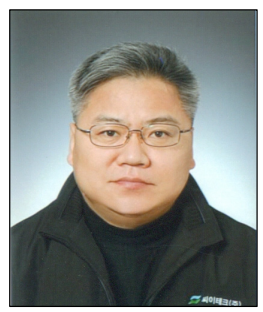

- 1987년 8월 : 영남대학교 기계공 학과(공학석사)

- 2001년 12월 현재 : (주)씨이 테크 대표이사

<관심분야>

대기오염제어기술, 열분해, 대기오염모델링

\section{김 민 철(Min-Choul Kim)}

[정회원]

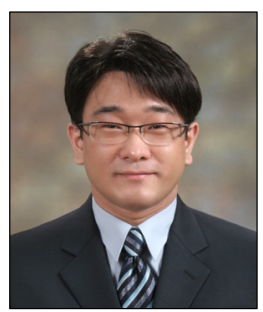

- 2003년 2월 : 동아대학교 환경공 학과(공학사)

- 2005년 2월 : 부산대학교 환경공 학과(공학석사)

- 2005년 2월 현재 : (주) 유성 중앙연구소 선임연구원

<관심분야>

산업폐기물처리, 소각로 해석 및 설계

이 재 정(Jae-Jeong Lee)

[정회원]

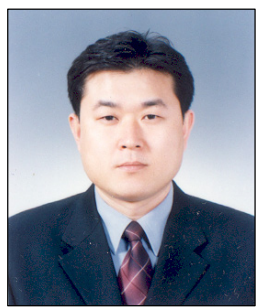

- 1996년 2월 : 부산대학교 환경공 학과(공학사)

- 1998년 2월 : 부산대학교 환경공 학과(공학석사)

- 2003년 8월 : 부산대학교 환경공 학과(공학박사)

- 2008년 2월 현재 : (주) 유성 중앙연구소 연구실장

<관심분야>

유해가스처리, 산업폐기물처리, 환경정책

이 강 우(Gang-woo Lee)

[정회원]

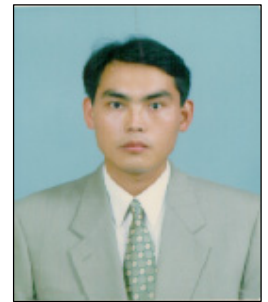

<관심분야>

산업폐기물처리, 소각로 해석 및 설계, 유해가스처리

- 1988년 2월 : 부산대학교 환경공 학과(공학사)

- 1995년 8월 : 부산대학교 환경공 학과 (공학석사)

- 2002년 8월 : 부산대학교 환경공 학과 (공학박사)

- 2004년 7월 현재 : (주) 유성 중앙연구소 소장

\section{[정회원]}

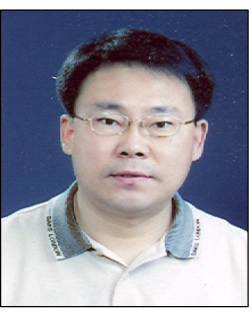

- 1990년 2월 : 부산대학교 환경공 학과(공학사)

- 1994년 2월 : 부산대학교 환경공 학과 (공학석사)

- 1997년 2월 : 부산대학교 환경공 학과 (공학박사)

- 1997년 3월 현재 : 한서대학 교 환경공학과 정교수

<관심분야>

대기오염제어(탈황 및 탈질), 폐기물처리, 이산화탄소 흡수 